\title{
Request for Unnecessary Prophylaxis
}

\section{Physicians should not write prescriptions for unnecessary prophylaxis in response to patients' anxiety about a perceived threat of bioterrorism.}

\author{
Commentary by Janet Keating, MD
}

Steven, a third-year family medicine resident, is reading the morning newspaper during his breakfast and sees that a "suspicious white powder" has been found on the floor of another building, this time a shopping mall. Tests from the powder found in a museum in Washington, DC the day prior have not yet been concluded. The media is abuzz with suspicions of anthrax, and public officials are advising people to remain "calm, but cautious." The newspaper article reminds readers that ciprofloxacin is the only drug approved by the FDA for prevention and treatment of anthrax. As Steven reads the article, he understands that this new discovery is unlike any before because the mall where the white powder was found is in a neighboring town. Many of his patients live there, and he suspects they will be frightened by the new find.

That afternoon in clinic, Steven sees one of his favorite patients, Mrs. Kelsey, a 45-year-old woman with diabetes. Mrs. Kelsey mentions the reports and asks Steven if she can have a prescription for ciprofloxacin. She hasn't been to the mall in which the powder was found and understands the whole thing may be a hoax but is worried nonetheless.

"It would just help me sleep a lot better at night if I could have the Cipro," she says, "Besides, I could just get it off the Internet, you know."

Steven realizes that he has no more knowledge about the likelihood that the powder contains anthrax spores than does Mrs. Kelsey, nor does he know the risk of future terrorist attacks. If Mrs. Kelsey had potentially been exposed, Steven wouldn't hesitate to write the prescription, but now he worries about the possibility of an Achilles tendon rupture and other adverse effects of ciprofloxacin. Moreover, he thinks that if he writes the prescription, he will probably be encouraging antibiotic resistance, which could potentially affect his entire population of patients.

On the other hand, Steven wants to care for Mrs. Kelsey's mental health, and he knows that she will likely be able to order Cipro on the Internet. What if more patients request the drug? If he writes the prescription for Mrs. Kelsey, shouldn't he write it for everyone else who requests it? Steven wishes he had thought this out before coming to clinic today.

\section{Commentary}

Steven considers several important questions in this case. The key question, though, is the one that he did not ask himself: if Mrs. Kelsey could get ciprofloxacin by other means, why did she come to her family doctor?

Because Mrs. Kelsey is frightened — she finds herself suddenly swept into a chaotic world where she has to be wary of something as innocent as a trip to the local mall. It does not matter that she is intelligent and well-informed on the facts available to the public about bioterrorism. Mrs. Kelsey is looking for reassurance that her world still has some order in it. By ordering Cipro on the Internet, she could gain some control over the immediate situation, but it leaves her fears unmitigated. 
Steven feels he lacks some of the information that would help him make a decision in this case, specifically, the nature of the powder found at the mall. The presence or absence of anthrax spores here is irrelevant, however, because Mrs. Kelsey was not exposed. There is no strictly medical indication to write a prescription for ciprofloxacin. Consideration of the risks and benefits of using Cipro in this case, then, occurs in the context of whether the antibiotic will relieve this patient's real problem: her fear and uncertainty. In her own words, having Cipro in her hand will help her "feel better."

In the short term, this might be true. A long-term solution, though, would be to help this patient understand what she really needs and why. Don't panic_-you don't need 45 minutes of counseling to get to the heart of the problem. Typically, a brief discussion of what constitutes exposure to a bioterrorism agent, the symptoms to be alert for, and reassurance that treatment is available if needed, will go along way toward reducing the patient's distress. Then, 1 or 2 well-framed questions will clarify the underlying cause of a patient's anxiety. For example, "What is it that most concerns you about this episode at the mall?" or "Have you thought about why having a bottle of Cipro at home will make you feel less worried?" When respect for patient autonomy and the patient's desire to participate in medical decisions conflict with what we, as clinicians, perceive as the best (beneficent) thing to do, communication is frequently the problem.

It can also be the solution. In my own practice, I had a patient who actually was in a building at the time when a white powder arrived in the mail that was later confirmed to contain anthrax spores. After getting specifics about the possible exposure, which turned out to be minimal if any, I asked what the patient was most worried about with this incident. "I'm not worried. I wasn't in the building that long," was the reply, "but my mother insisted I see a doctor."

Steven should be honest with Mrs. Kelsey. It is all right to tell her that ciprofloxacin is not necessary and that ordering it from a Web site is unsafe. She is not necessarily looking for a prescription. By asking her what she thinks would help to keep her healthy and reduce her anxiety, Steven is still welcoming his patient to participate in the decisionmaking process. She is likely to decide that all she really needs is reassurance that a prescription would be available to her if she needed it. If Mrs. Kelsey insists on a prescription, however, Steven will have a more difficult decision to make: weighing the risks of giving her ciprofloxacin against the risks of damaging his relationship with this established patient. Whatever he decides, how he communicates that decision is ultimately what maintains the relationship and builds the respect and trust necessary to care for the patient.

\section{Related Resource}

- Brody H. The Healer's Power. New Haven, Conn: Yale University Press; 1993.

Janet Keating, MD, is an assistant consulting professor in the Department of Community and Family Medicine at Duke University and is a faculty associate of Duke's Center for the Study of Medical Ethics and the Humanities. She is in private practice in the Raleigh-Durham area.

The people and events in this case are fictional. Resemblance to real events or to names of people, living or dead, is entirely coincidental. The viewpoints expressed on this site are those of the authors and do not necessarily reflect the views and policies of the AMA.

(C) 2004 American Medical Association. All Rights Reserved. 